\section{Cureus}

\title{
Naproxen and Diclofenac Attenuate Atorvastatin-induced Preconditioning of the Myocardium
}

Zoltan Varga ${ }^{1}$, Martina Nemcekova ${ }^{2}$, Slavka Carnicka ${ }^{2}$, Veronika Slezakova ${ }^{3}$, Miriam Petrova $^{3}$, Marek Majdan ${ }^{4}$, Tana Ravingerova ${ }^{2}$, Viera Kristova ${ }^{3}$

1. Internal Medicine Residency, Florida Hospital-Orlando 2. Institute for Heart Research, Slovak Academy of Sciences 3. Department of Pharmacology and Clinical Pharmacology, Comenius University in Bratislava 4. Department of Public Health, Trnava University

$\square$ Corresponding author: Zoltan Varga, zoltan.varga.md.phd@gmail.com Disclosures can be found in Additional Information at the end of the article

\section{Abstract}

Statins reduce infarct size (IS) in ischemia-reperfusion injury of the myocardium. Inhibition of cyclooxygenase-2 (COX-2) attenuates this benefit. We investigated the effect of two widely used non-selective non-steroidal anti-inflammatory drugs (NSAIDs) with different degree of antiCOX-2 activity on atorvastatin-mediated preconditioning. Wistar rats received oral atorvastatin $\left(10 \mathrm{mg} \bullet \mathrm{kg}^{-1} \bullet\right.$ day $\left.^{-1}\right)$, naproxen $\left(10 \mathrm{mg} \bullet \mathrm{kg}^{-1} \bullet \mathrm{day}^{-1}\right)$, diclofenac $\left(8 \mathrm{mg} \bullet \mathrm{kg}^{-1} \bullet \mathrm{day}^{-1}\right)$, atorvastatin+naproxen, atorvastatin+diclofenac or water for three days. Hearts were then excised and perfused in the Langendorff system. Area at risk (AR) and IS were determined after $30 \mathrm{~min}$ of regional ischemia and $120 \mathrm{~min}$ of reperfusion. Atorvastatin reduced IS by $51.3 \%$ compared with controls $(14.7 \pm 3.9 \%$ vs. $30.2 \pm 4.6 \%$ of the AR; $P<0.001)$. Naproxen and diclofenac alone did not alter IS compared to control. Diclofenac completely abrogated atorvastatin-mediated protection of the myocardium. Naproxen significantly attenuated but did not eliminate the IS reducing the effect of atorvastatin when compared with controls $(P=$ 0.038). The difference in IS between the atorvastatin+naproxen group and the atorvastatin+diclofenac group showed a strong trend in reaching statistical significance $(P=$ 0.058), but was not found to be significant. Our results suggest relatively small, but noticeable differences among non-selective NSAIDs in their potential to attenuate statin-mediated preconditioning.

Categories: Internal Medicine, Cardiology, Pain Management

Keywords: preconditioning, cyclooxygenase-2, atorvastatin, naproxen, diclofenac, myocardial infarction

Received 04/11/2017 Review began 04/18/2017 Review ended 04/24/2017 Published 04/29/2017

\section{(c) Copyright 2017}

Varga et al. This is an open access article distributed under the terms of the Creative Commons Attribution License CC-BY 3.0., which permits unrestricted use, distribution, and reproduction in any medium, provided the original author and source are credited.

\section{Introduction}

Inhibitors of 3-hydroxy-3-methylglutaryl coenzyme A reductase (statins) are widely used in the treatment of patients at the time or after various forms of acute coronary syndromes (ACS). Guidelines advocate the early initiation of statin therapy in ACS irrespective of cholesterol levels [1-2]. The benefit of statins is likely achieved partially by cholesterol-independent (pleiotropic) effects [3]. One of these pleiotropic effects is an increase in resistance of myocardium to ischemia-reperfusion (IR) injury.

Guidelines for the management of ST-elevation myocardial infarction call for the investigation of new pharmacological strategies to help minimize the consequences of IR injury. One of the 
possibilities is to take advantage of the protective effect of statins, which according to guidelines, requires further study [2].

Administration of statins before myocardial ischemia, during ischemia or reperfusion, exhibited an infarct size (IS) limiting the effect in animal experiments [4-7]. Clinical trials suggest that pre percutaneous coronary intervention (pre-PCI) administration of atorvastatin might be of substantial benefit [8-15]. Similarly, positive results were reported after pretreatment with rosuvastatin [8-9,16-18]. If future studies confirm this data, high dose statin pre-treatment before PCI might become standard practice.

The mechanism of statin-mediated protection has not yet been fully understood, but animal experiments have shown that the activity of cyclooxygenase-2 (COX-2) seems to be necessary, while cyclooxygenase-1 seems to be non-essential. Administration of selective COX-2 inhibitors attenuates the IS limiting effect of statins in animal models of IR injury of the myocardium $[5,19]$. In humans, selective COX-2 inhibition abolishes the protective effect of rosuvastatin on IR-induced endothelial dysfunction in the radial artery [20]. In rats, acetylsalicylic acid, a non-selective COX inhibitor with dose-dependent anti-COX-2 activity, blunted the IS limiting effect of atorvastatin in a dose-dependent manner [6]. This brings up the possibility of significant differences among individual non-selective non-steroidal antiinflammatory drugs (NSAIDs) with different anti-COX-2 activity in their potential to interact with the IS-limiting effect of statins.

Aims: 1) To determine, if naproxen and diclofenac, two widely used non-selective NSAIDs with different anti-COX-2 activity [21], interfere with atorvastatin-mediated protection of myocardium from IR injury; 2) to determine, if there are significant differences in the level of attenuation of IS-limiting effect of atorvastatin between the two drugs; 3 ) to determine the effect of the administered medicine on incidence and severity of IR-induced arrhythmias during the protocol.

\section{Materials And Methods}

\section{Animal care}

Experiments were conducted on male Wistar rats (Department of Toxicology and Laboratory Animals Breeding Detached Branch, Dobra Voda, Slovakia) (body weight of $300 \pm 19$ g), which were fed a standard diet, tap water ad libitum and received humane care in accordance with the guide for the care and use of laboratory animals (Eight edition, NRC 2011). The study was approved by the Ethics Committee of the Institute for Heart Research of the Slovak Academy of Sciences and by the Animal Health and Animal Welfare Division of the State Veterinary and Food Administration of the Slovak Republic.

\section{Materials}

Naproxen, diclofenac, thiopental and heparin were purchased from Sigma-Aldrich (Prague, Czech Republic). Atorvastatin was purchased from Zentiva Slovakia (Bratislava, Slovakia).

\section{Pre-treatment}

All drugs were dissolved in water and administered for three days by oral gavage. The three-day duration of pre-treatment was chosen for comparability and consistency since this duration was used in most prior similar experiments. Control animals received water by oral gavage. Rats were randomly divided into six groups: group one (control), group two (atorvastatin), group three (naproxen), group four (diclofenac), group five (atorvastatin+naproxen) and group six (atorvastatin+diclofenac). The drugs were administered once daily in the following doses: 
atorvastatin $-10 \mathrm{mg} \bullet \mathrm{kg}-1 \bullet$ day-one, naproxen $-10 \mathrm{mg} \bullet \mathrm{kg}-1 \bullet$ day-one, diclofenac $-8 \mathrm{mg} \bullet \mathrm{kg}$ $1 \bullet$ day-one. On the fourth day, rats were euthanized and their hearts excised.

The selected doses of drugs are in line with those used in prior experiments in animal models; the doses of naproxen and diclofenac administered provide approximately equipotent analgesic/anti-inflammatory effects according to published data [5-7,22-25].

\section{Perfusion protocol}

Rats were anesthetized by intraperitoneal application of thiopental $(60 \mathrm{mg} \bullet \mathrm{kg}-1)+$ heparin (500 IU). After the onset of deep anesthesia, hearts were rapidly excised and placed into cold perfusion buffer. Hearts were perfused in the Langendorff system after cannulation via the aorta at a constant pressure of $70 \mathrm{~mm} \mathrm{Hg}$ at $37^{\circ} \mathrm{C}$. Perfusion solution was a modified KrebsHenseleit buffer gassed with 95\% oxygen $(\mathrm{O} 2)$ and five percent carbon di oxide $(\mathrm{CO} 2)(\mathrm{pH}=7.4)$ containing (in mmol $\bullet \mathrm{L}-1)$ sodium chloride $(\mathrm{NaCl})(118.0)$, potassium chloride is $(\mathrm{KCl})(3.2)$, magnesium sulfate (MgSO4) (1.2), sodium bicarbonate (NaHCO3) (25.0), monopotassium phosphate (KH2PO4) (1.18), calcium chloride $(\mathrm{CaCl} 2)(2.5)$ and glucose (7.0). Contaminants were removed from the solution via filtering through a $5 \mu \mathrm{m}$ porosity filter (Millipore, Billerica, Massachusetts, USA). Electrical activity of the heart was registered by means of two electrodes made of stainless steel attached to the apex of the heart and the aortic cannula. Left ventricular (LV) pressure was measured by means of a nonelastic water-filled balloon inserted into the LV cavity through the left atrium and connected to a pressure transducer (MLP844; ADInstruments, Spechbach, Germany). Target end-diastolic pressure was 5-7 mm Hg. LV systolic pressure (LVSP), LV diastolic pressure (LVDiP), LV developed pressure (LVDP; systolic diastolic), maximal rates of pressure development and fall, $+(\mathrm{dp} / \mathrm{dt}) \max$ and $-(\mathrm{dp} / \mathrm{dt}) \max$, heart rate (HR; derived from the electrogram) and coronary flow (CF) were measured and recorded throughout the protocol. All parameters and arrhythmias were analyzed with PowerLab/8SP Chart 5 software (ADInstruments, Spechbach, Germany). The ligature (Mersilk black W 582, Johnson \& Johnson, Bratislava, Slovakia) for induction of regional ischemia was placed loosely around the left anterior descending coronary artery (LAD), close to its origin, immediately after cannulation of the heart. A traction type plastic occluder was placed on the suture, without compromising blood flow through the artery.

The isolated hearts underwent 15 minutes of stabilization period. Regional ischemia was induced by constricting the myocardium around LAD with the use of the ligature and plastic occluder. Reduction of CF by approximately $40 \%$ was targeted. The release of the ligature with subsequent reperfusion was done after 30 minutes. The success of reperfusion was verified by monitoring the increase of CF. The 30 minutes of ischemia were followed by 120 minutes of reperfusion. The ischemia and reperfusion protocol was consistent with our previous experiments [26].

\section{Determination of infarct size and area at risk}

The IS and size of the area at risk (AR) were delineated by double staining with five percent potassium permanganate and 2, 3, 5-triphenyltetrazolium chloride and determined by a computerized planimetric method, as described earlier [26]. Infarct size was expressed both as a percentage of AR and of the left ventricle.

\section{Arrhythmia quantification}

Electrical activity of the heart was recorded during stabilization, ischemia and the first 10 minutes of reperfusion. The recorded electrogram was analyzed in accordance with the Lambeth Conventions [27]. The focus was on quantification of the number of premature ventricular contractions (PVC), incidence and duration of episodes of ventricular tachycardia 


\section{Cureus}

(VT), four or more consecutive ectopic beats and incidence and duration of ventricular fibrillation (VF).

\section{Statistical analysis}

Data are presented as arithmetic means \pm standard deviation (SD). The statistical differences between groups were studied using two-way analysis of variance (ANOVA). Post hoc comparisons were done with Tukey correction for multiple comparisons. The analysis was performed with the use of statistical software SPSS for Windows, version 19 (IBM SPSS Inc. Chicago, IL, USA). As a threshold for statistical significance, a P value of ${ }^{<} 0.05$ was set.

\section{Results}

The protocol included 57 Wistar rats, each of the groups contained nine or 10 animals. A total of six isolated hearts were excluded from the experiment, three because of no signs of sufficient ischemia after coronary artery ligation, one because of no sign of reperfusion after release of the ligature, one because of permanent total loss of contractile function during the protocol and the last one because of a problem with determination of the size of infarction.

There were no significant differences between the groups in the number of excluded isolated hearts, body weight or in the values of HR, LVSP, LVDiP, LVDP and CF at baseline, i.e., prior to ischemia (Table 1).

\begin{tabular}{|lllllll|}
\hline & Control & NAP & DIC & ATV & ATV+NAP & ATV+DIC \\
\hline N & 9 & 8 & 8 & 8 & 9 & 9 \\
HR (beats/min) & $283 \pm 28$ & $255 \pm 38$ & $270 \pm 27$ & $266 \pm 47$ & $281 \pm 60$ & $280 \pm 40$ \\
LVSP (mmHg) & $97.2 \pm 16.6$ & $89.1 \pm 10.5$ & $87.8 \pm 13.1$ & $87.9 \pm 10.5$ & $86.5 \pm 10.1$ & $80.0 \pm 16$ \\
LVDiP (mmHg) & $5.1 \pm 2.2$ & $7.1 \pm 4.7$ & $6.1 \pm 0.7$ & $4.4 \pm 1.7$ & $6.0 \pm 1.4$ & $6.4 \pm 1.4$ \\
LVDP (mmHg) & $92.0 \pm 18.5$ & $82.0 \pm 13.3$ & $81.7 \pm 13.3$ & $83.5 \pm 11.2$ & $80.5 \pm 11.2$ & $73.6 \pm 16.7$ \\
CF (ml/min) & $9.5 \pm 1.2$ & $8.0 \pm 2.3$ & $8.4 \pm 1.3$ & $7.3 \pm 1.1$ & $7.3 \pm 1.2$ & $8.8 \pm 2.5$
\end{tabular}

TABLE 1: Values (mean \pm standard deviation) of heart rate (HR), left ventricular systolic pressure (LVSP), left ventricular diastolic pressure (LVDiP), left ventricular developed pressure (LVDP) and coronary flow (CF) at baseline

$\mathrm{n}=$ number of animals in the group; ATV - atorvastatin, NAP - naproxen, DIC - diclofenac

\section{Infarct size and area at risk protocol}

No significant differences in body weight and AR were found between the groups (Table 2). 


\section{Cureus}

\begin{tabular}{|c|c|c|c|c|c|c|c|}
\hline & Control & NAP & DIC & ATV & ATV + NAP & ATV + DIC & $P$ value \\
\hline$N$ & 9 & 8 & 8 & 8 & 9 & 9 & \\
\hline Body weight, g & $300 \pm 19$ & $301 \pm 18$ & $299 \pm 11$ & $303 \pm 22$ & $297 \pm 19$ & $302 \pm 23$ & 0.985 \\
\hline AR volume, mg & $440 \pm 65$ & $521 \pm 83$ & $432 \pm 67$ & $414 \pm 104$ & $412 \pm 86$ & $456 \pm 110$ & 0.352 \\
\hline AR (\% of LV) & $49.1 \pm 8.2$ & $53.1 \pm 8.9$ & $52.9 \pm 9.3$ & $50.9 \pm 7.9$ & $52.7 \pm 9.8$ & $52.4 \pm 11.3$ & 0.961 \\
\hline IS (\% of AR) & $30.2 \pm 4.6$ & $30.5 \pm 2.6$ & $29.9 \pm 4.4$ & $14.7 \pm 3.9$ & $24.0 \pm 5.3$ & $29.8 \pm 3.9$ & $<0.001$ \\
\hline IS (\% of LV) & $15.0 \pm 3.6$ & $16.2 \pm 3.1$ & $16.0 \pm 4.7$ & $7.2 \pm 1.2$ & $12.5 \pm 2.7$ & $16.6 \pm 4.6$ & $<0.001$ \\
\hline
\end{tabular}

TABLE 2: Body weight, volume of area at risk (AR), size of area at risk shown as percentage of the left ventricle (LV), infarct size (IS) shown as percentage of the area at risk and infarct size shown as percentage of the left ventricle

Data shown as mean \pm standard deviation; $\mathrm{n}=$ number of animals in the group; ATV - atorvastatin, NAP - naproxen, DIC - diclofenac

Infarct size calculated as percentage of the area at risk, did not differ from control (30.2 $\pm 4.6 \%)$ for naproxen $(30.5 \pm 2.6 \%)$ or diclofenac $(29.9 \pm 4.4 \%)(\mathrm{P}=0.99$ for both) (Figure 1).

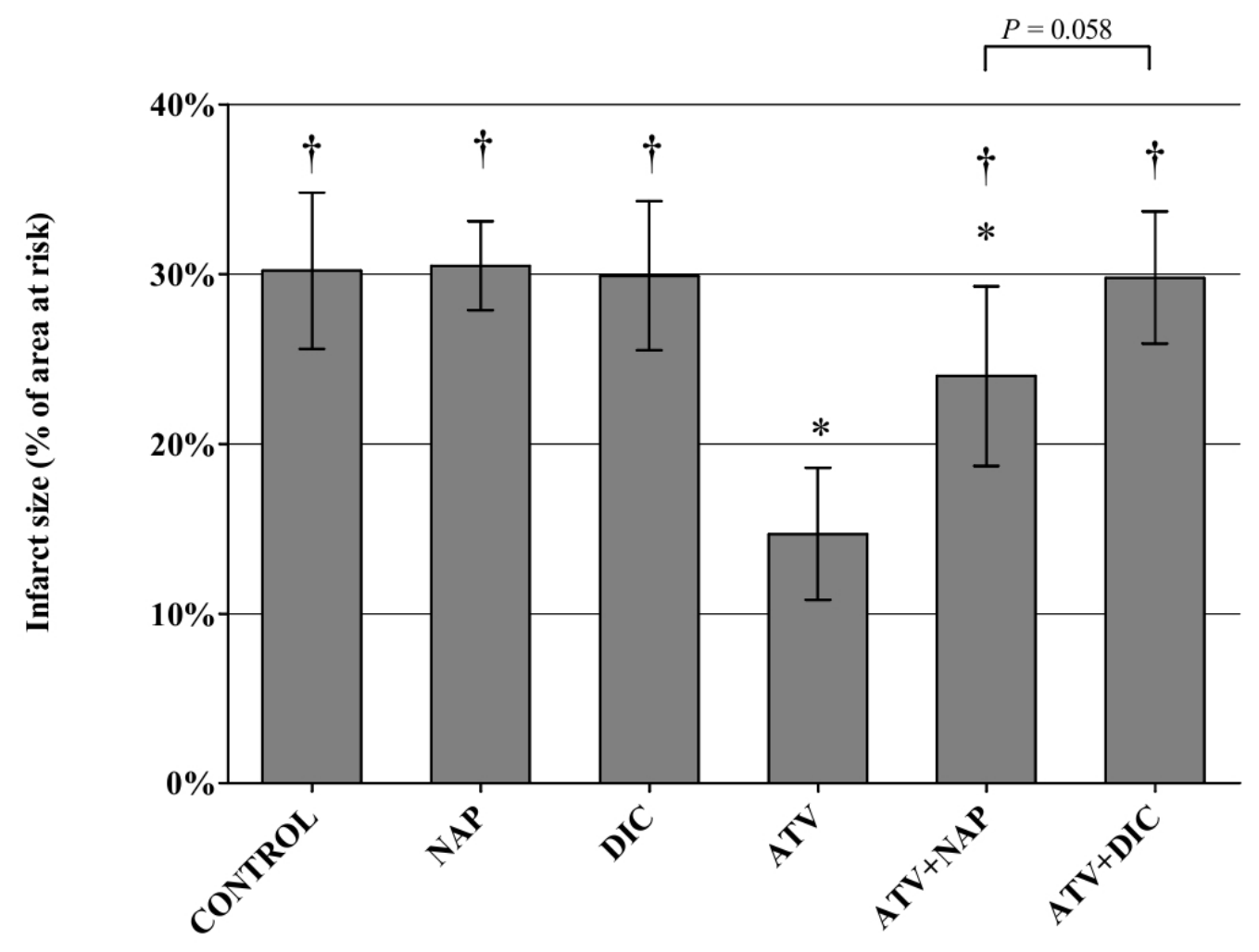

FIGURE 1: Infarct size, calculated as percentage from the area at risk after $\mathbf{3 0}$ minutes of ischemia and $\mathbf{1 2 0}$ minutes of reperfusion

Values shown as mean \pm standard deviation. $N=$ control -9 , naproxen (NAP) - 8, diclofenac (DIC) - 


\section{Cureus}

8, atorvastatin (ATV) - 8, ATV+NAP - 9, ATV+DIC - 9; † - P < 0.05 when compared to ATV, * $-\mathrm{P}<$ 0.05 when compared to controls

Pre-treatment with atorvastatin $(14.7 \pm 3.9 \%)$ significantly $(\mathrm{P}<0.001)$ reduced infarct size compared with the control group (Figure 1). The IS was reduced by $51.3 \%$. Both naproxen plus atorvastatin and diclofenac plus atorvastatin displayed significant attenuation of the infarct size limiting effect of atorvastatin alone ( $\mathrm{P}<0.001$ for both) (Figure 1). Atorvastatin mediated reduction of IS was less affected by co-administration of naproxen than co-administration of diclofenac $(24.0 \pm 5.3 \%$ vs. $29.8 \pm 3.9 \%)$, but the difference did not quite reach statistical significance $(\mathrm{P}=0.058)$. IS in the atorvastatin+diclofenac group was comparable to controls $(\mathrm{P}=$ $0.99)$, but a significantly smaller IS was found in the atorvastatin+naproxen group than in controls $(\mathrm{P}=0.038)$.

Analysis of IS calculated as a percentage of left ventricular mass yielded similar results, but there was no significant difference between atorvastatin+naproxen and controls (Figure 2).

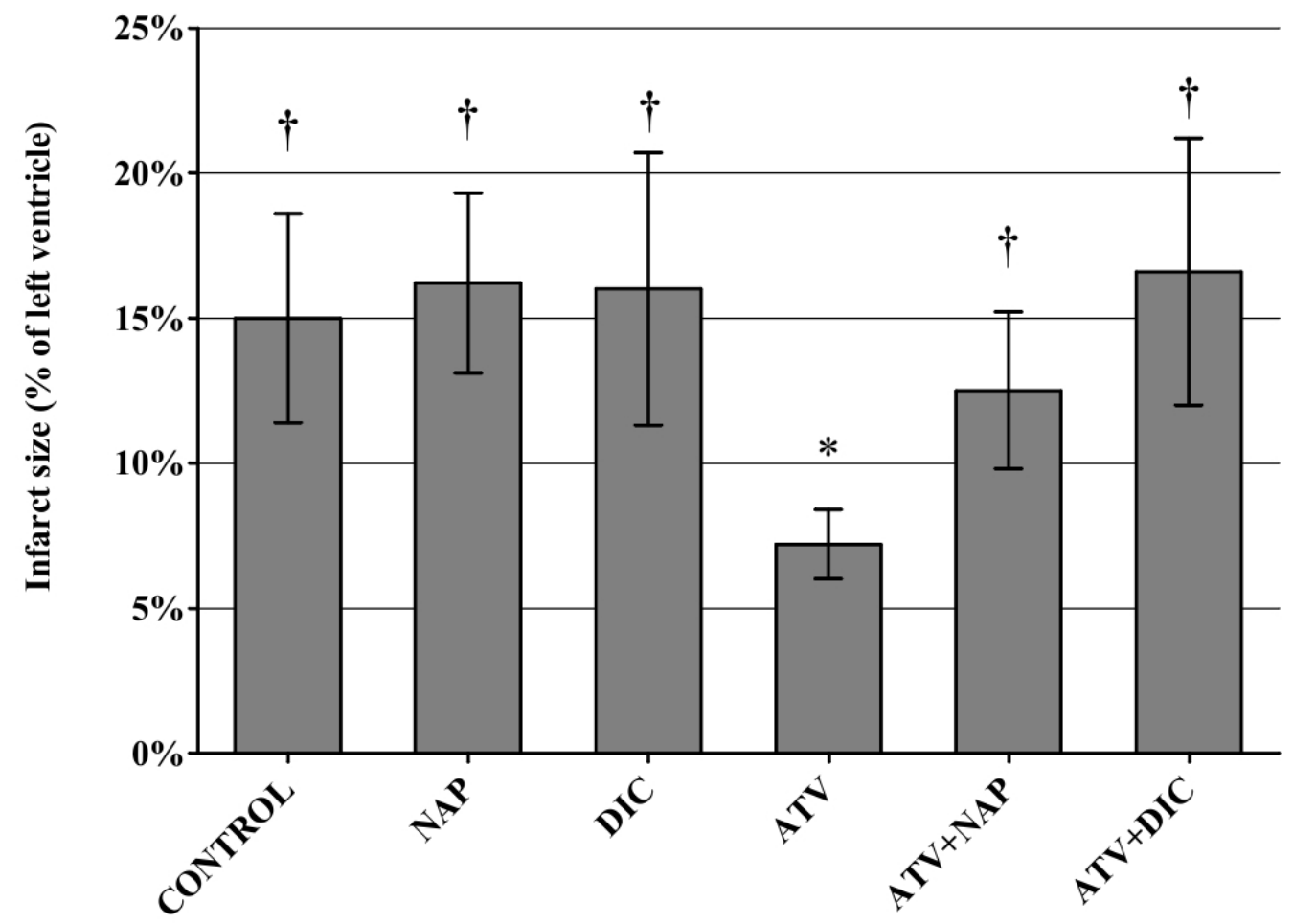

FIGURE 2: Infarct size calculated as percentage from the volume of left ventricle after $\mathbf{3 0}$ minutes of ischemia and 120 minutes of reperfusion

Values shown as mean \pm standard deviation. $N=$ control - 9, naproxen (NAP) - 8, diclofenac (DIC) 8, atorvastatin (ATV) - 8, ATV+NAP - 9, ATV+DIC - 9; $\dagger-\mathrm{P}<0.05$ when compared to ATV, * $-\mathrm{P}<$ 0.05 when compared to controls

\section{Arrhythmias}

Administration of naproxen or diclofenac did not affect the number of PVCs. The overall 


\section{Cureus}

number of PVCs during the whole protocol was lower in the atorvastatin group than in controls, but without statistical significance $(\mathrm{P}=0.334)$ (Table 3).

\begin{tabular}{|c|c|c|c|c|c|c|c|c|c|c|c|c|}
\hline \multirow{3}{*}{$N$} & \multicolumn{2}{|c|}{ Control } & \multicolumn{2}{|l|}{ NAP } & \multicolumn{2}{|l|}{ DIC } & \multicolumn{2}{|l|}{ ATV } & \multicolumn{2}{|c|}{ ATV + NAP } & \multicolumn{2}{|c|}{ ATV + DIC } \\
\hline & 9 & & 8 & & 8 & & 8 & & 9 & & 9 & \\
\hline & isch. & rep. & isch. & rep. & isch. & rep. & isch. & rep. & isch. & rep. & isch. & rep. \\
\hline $\begin{array}{l}\text { Number of } \\
\text { PVCs }\end{array}$ & $\begin{array}{l}495 \pm \\
153\end{array}$ & $\begin{array}{l}296 \pm \\
51\end{array}$ & $\begin{array}{l}516 \pm \\
259\end{array}$ & $\begin{array}{l}321 \pm \\
85\end{array}$ & $\begin{array}{l}456 \pm \\
179\end{array}$ & $\begin{array}{l}295 \pm \\
87\end{array}$ & $\begin{array}{l}330 \pm \\
193\end{array}$ & $\begin{array}{l}252 \pm \\
58\end{array}$ & $\begin{array}{l}348 \pm \\
188\end{array}$ & $\begin{array}{l}300 \pm \\
106\end{array}$ & $\begin{array}{l}372 \pm \\
207\end{array}$ & $\begin{array}{l}318 \pm \\
117\end{array}$ \\
\hline $\begin{array}{l}\text { Number of VT } \\
\text { episodes }\end{array}$ & $\begin{array}{l}30.1 \pm \\
17.3\end{array}$ & $\begin{array}{l}8.7 \pm \\
3,3\end{array}$ & $\begin{array}{l}30.6 \pm \\
19.9\end{array}$ & $\begin{array}{l}8.4 \pm \\
2.9\end{array}$ & $\begin{array}{l}29.6 \pm \\
20.7\end{array}$ & $\begin{array}{l}8.6 \pm \\
3.7\end{array}$ & $\begin{array}{l}20.1 \pm \\
14.7\end{array}$ & $\begin{array}{l}6.9 \pm \\
2.4\end{array}$ & $\begin{array}{l}19.7 \pm \\
12.3\end{array}$ & $\begin{array}{l}8.7 \pm \\
3.7\end{array}$ & $\begin{array}{l}22.2 \pm \\
14.1\end{array}$ & $\begin{array}{l}8.3 \pm \\
6.1\end{array}$ \\
\hline $\begin{array}{l}\text { Duration of VT } \\
\text { (s) }\end{array}$ & $\begin{array}{l}39.6 \pm \\
19.9\end{array}$ & $\begin{array}{l}34.1 \pm \\
16.6\end{array}$ & $\begin{array}{l}44.1 \pm \\
31.1\end{array}$ & $\begin{array}{l}39.1 \pm \\
17.9\end{array}$ & $\begin{array}{l}37.8 \pm \\
21.5\end{array}$ & $\begin{array}{l}33.6 \pm \\
19.2\end{array}$ & $\begin{array}{l}24.3 \pm \\
16.9\end{array}$ & $\begin{array}{l}27.9 \pm \\
11.3\end{array}$ & $\begin{array}{l}25.6 \pm \\
17.0\end{array}$ & $\begin{array}{l}36.2 \pm \\
18.7\end{array}$ & $\begin{array}{l}27.6 \pm \\
18.1\end{array}$ & $\begin{array}{l}36.9 \pm \\
24.8\end{array}$ \\
\hline
\end{tabular}

Data shown as mean \pm standard deviation; $n=$ number of animals in the group; ATV - atorvastatin, NAP - naproxen, DIC - diclofenac

The mean number of PVCs in groups atorvastatin+naproxen and atorvastatin+diclofenac was lower than in controls and higher than in the atorvastatin group, but the differences were not statistically significant.

Number of VT episodes during the whole protocol was not influenced by naproxen or diclofenac (Table 3). Although the number of VT episodes in the atorvastatin group was lower than in controls during ischemia, reperfusion and also the total duration of the protocol, the difference was not found significant. A number of VT episodes was similar in the atorvastatin, atorvastatin+naproxen and atorvastatin+diclofenac groups.

Duration of VT episodes was not affected by administration of naproxen or diclofenac (Table 3). No significant reduction of VT episode duration was observed in the atorvastatin group, although duration was shorter than in controls. Duration of VT episodes was similar in the atorvastatin, atorvastatin+naproxen and atorvastatin+diclofenac groups.

An episode of VF occurred in just two isolated hearts, one in the control, and the other in the naproxen group.

\section{Discussion}

In the present study, we demonstrated that three-day pre-treatment with atorvastatin reduced IS by $51.3 \%$. Two non-selective NSAIDs, naproxen and diclofenac, interfered with atorvastatinmediated cardioprotection. The IS limiting effect of atorvastatin was completely abrogated by diclofenac. Although naproxen significantly attenuated the IS limiting effect of atorvastatin, co-administration of atorvastatin and naproxen still resulted in significantly reduced size of area of myocardial necrosis when compared to controls. The difference in IS between the atorvastatin+naproxen group and the atorvastatin+diclofenac group was close to reaching statistical significance $(\mathrm{P}=0.058)$. 
The seemingly greater potential of diclofenac compared to naproxen to alleviate the IS reducing effect of atorvastatin might be related to its more pronounced COX-2 inhibitory activity. Previously, it was shown that a high therapeutic dose of diclofenac suppresses the activity of COX-2 to higher degree than a high therapeutic dose of naproxen [21]. It is known that administration of selective COX-2 inhibitors attenuates statin-mediated, increase in resistance of myocardium to IR [5,19]. Administration of various doses of acetylsalicylic acid, a nonselective inhibitor of COX, dose-dependently blunts the IS limiting effect of atorvastatin [6]. These findings show the importance of the degree of COX-2 inhibition on the interaction between statins and COX inhibitors. Since therapeutic doses of various non-selective NSAIDs block COX-2 to a different extent, significant differences may exist in the potential to decrease statin-mediated cardioprotection in the setting of IR. To our knowledge, no prior study evaluated this hypothesis.

Experiments about effects of statins on IR-induced arrhythmias yielded inconsistent results. Short-term administration of pravastatin elicited protective effect against IR-induced arrhythmias in ex-vivo animal models of IR injury [28]. On the other hand, a single dose of pravastatin two hours before ischemia had no protective effect under in-vivo conditions [29]. In the present experiment, atorvastatin did not offer statistically significant protection from IRinduced arrhythmias. However, the overall number of PVCs and VT episodes was lower and the duration of VT episodes shorter in the atorvastatin group than in controls. The lack of statistically significant antiarrhythmic effect in our experiment is in contrast with previously published results of ex-vivo experiments with other statins. We can speculate that the different outcome might be caused by molecular properties of atorvastatin, by differences in the experimental protocol, or by the relatively small size of the experimental groups leading to potential beta error ( $\beta$-error). Further research is needed to clarify the antiarrhythmic properties of atorvastatin in the setting of myocardial ischemia.

The results of our experiment could have significant clinical implications. Patients with ischemic heart disease often possess comorbidities that result in short- or long-term treatment with analgesics. NSAIDs are used weekly by $70 \%$ of patients over age 65 and $34 \%$ of them take a NSAID at least once per day [30]. These data demonstrate the extent that treatment with NSAIDs could have pleiotropic effects of statins. As demonstrated by Liuni, et al., short term rosuvastatin administration protects from IR-induced endothelial dysfunction in humans. Celecoxib, a selective COX-2 inhibitor, blunted this effect [20]. If confirmed in clinical studies, our results bring up the possibility of clinically significant differences between various nonselective NSAIDs in their potential to diminish the benefit of pre-procedural statin administration in the setting of elective or urgent percutaneous coronary intervention (PCI). Naproxen rather than diclofenac might be better suited for analgesic treatment of patients at risk of ACS, because, at least in our animal model, it does not completely abrogate the IS limiting effect of pre-PCI statin administration. According to our results and previously published data, even non-selective NSAIDs with less pronounced anti-COX-2 activity have the potential to, at least partially, attenuate statin-mediated reduction of IS. It might be reasonable to stop administration of such drugs if elective PCI with pre-procedural statin administration is scheduled in a patient.

\section{Conclusions}

In conclusion, we can summarize our findings as follows: 1) Three-day atorvastatin administration led to a significant reduction of IS; 2) Three-day administration of both naproxen and diclofenac significantly attenuated the IS limiting effect of atorvastatin; 3) Diclofenac completely abrogated atorvastatin-mediated protection of the myocardium. In contrast, naproxen, the non-selective NSAID with less anti-COX-2 activity, attenuated the IS reducing effect of atorvastatin, but compared with controls, co-administration of atorvastatin 
and naproxen still lead to significantly reduced IS; 4) Although, overall numbers of premature ventricular contraction (PVCs) and ventricular tachycardia (VT) episodes were lower in the atorvastatin group, atorvastatin failed to offer significant protection from arrhythmias.

Our results suggest potentially meaningful differences between various non-selective NSAIDs in their potential to attenuate statin-mediated protection from IR injury. Further studies are needed to evaluate the possible clinical significance of these differences in treatment of patients with ischemic heart disease, who are in need of NSAID administration.

The limitations of our study include the ex-vivo design, the fact that COX-2 activity in myocardial tissue after drug administration was not tested, just extrapolated from prior data and the use of only one dosage of each NSAID making impossible to detect dose-dependent changes in effect. Also, we have to mention that direct extrapolation of the results obtained in this animal experiment to human subjects is impossible, although human studies previously discussed in this paper indicate a similar role of COX-2 in ischemia and reperfusion in human and rats.

\section{Additional Information \\ Disclosures}

Human subjects: All authors have confirmed that this study did not involve human participants or tissue. Animal subjects: Animal Health and Animal Welfare Division of the State Veterinary and Food Administration of the Slovak Republic Issued protocol number 9099/03-220. Conflicts of interest: In compliance with the ICMJE uniform disclosure form, all authors declare the following: Payment/services info: This work was supported by the Scientific Grant Agency of Ministry of Education, Science, Research and Sports of Slovak Republic (Vedecka Grantova Agentura Ministerstva Skolstva, Vedy, Vyskumu a Sportu Slovenskej Republiky) [grant VEGA 1/0501/11]; Comenius University (Univerzita Komenskeho) [grant GUK 408/2011]; and the Slovak Research and Development Agency (Agentura na Podporu Vyskumu a Vyvoja) [grant APVV-0102-11]. The grant providers played no role in the design, methods, data collection, analysis and interpretation of the data, preparation of the paper or in the decision to submit the manuscript. Financial relationships: All authors have declared that they have no financial relationships at present or within the previous three years with any organizations that might have an interest in the submitted work. Other relationships: All authors have declared that there are no other relationships or activities that could appear to have influenced the submitted work.

\section{Acknowledgements}

We thank the research team of the Institute for Heart Research of the Slovak Academy of Sciences and the team of the Department of Pharmacology and Clinical Pharmacology of the Medical Faculty of Comenius University for their assistance and support. This work was supported by the Scientific Grant Agency of Ministry of Education, Science, Research and Sports of Slovak Republic (Vedecka Grantova Agentura Ministerstva Skolstva, Vedy, Vyskumu a Sportu Slovenskej Republiky) [grant VEGA 1/0501/11]; Comenius University (Univerzita Komenskeho) [grant GUK 408/2011]; and the Slovak Research and Development Agency (Agentura na Podporu Vyskumu a Vyvoja) [grant APVV-0102-11]. The grant providers played no role in the design, methods, data collection, analysis, and interpretation of the data, preparation of the paper or in the decision to submit the manuscript.

\section{References}

1. Amsterdam EA, Wenger NK, Brindis RG, et al: 2014 AHA/ACC guideline for the management of patients with non-ST-elevation acute coronary syndromes: a report of the American 
College of Cardiology/American Heart Association task force on practice guidelines. J Am Coll Cardiol. 2014, 64:139-228. 10.1016/j.jacc.2014.09.017

2. O'Gara PT, Kushner FG, Ascheim DD, et al: 2013 ACCF/AHA guideline for the management of ST-elevation myocardial infarction: a report of the American College of Cardiology Foundation/American Heart Association task force on practice guidelines. Circulation. 2013, 127:529-555. 10.1161/CIR.0b013e3182742cf6

3. Ludman A, Venugopal V, Yellon DM, et al.: Statins and cardioprotection-more than just lipid lowering?. Pharmacol Ther. 2009, 122:30-43. 10.1016/j.pharmthera.2009.01.002

4. Lefer AM, Campbell B, Shin YK, et al.: Simvastatin preserves the ischemic-reperfused myocardium in normocholesterolemic rat hearts. Circulation. 1999, 100:178-184. 10.1161/01.CIR.100.2.178

5. Birnbaum Y, Ye Y, Rosanio S, et al.: Prostaglandins mediate the cardioprotective effects of atorvastatin against ischaemia-reperfusion injury. Cardiovasc Res. 2005, 65:345-355. 10.1016/j.cardiores.2004.10.018

6. Birnbaum Y, Lin Y, Ye Y, et al: Aspirin before reperfusion blunts the infarct size limiting effect of atorvastatin. Am J Physiol Heart Circ Physiol. 2007, 292:2891-2897. 10.1152/ajpheart.01269.2006

7. Ye Y, Martinez JD, Perez-Polo RJ, et al.: The role of eNOS, iNOS, and NF-kappaB in upregulation and activation of cyclooxygenase- 2 and infarct size reduction by atorvastatin. Am J Physiol Heart Circ Physiol. 2008, 295:343-351. 10.1152/ajpheart.01350.2007

8. Tentzeris I, Rohla M, Jarai R, et al: Influence of high-dose highly efficient statins on shortterm mortality in patients undergoing percutaneous coronary intervention with stenting for acute coronary syndromes. Am J Cardiol. 2014, 113:1099-1104. 10.1016/j.amjcard.2013.12.012

9. Sardella G, Lucisano L, Mancone M, et al: Comparison of high reloading rosuvastatin and atorvastatin pretreatment in patients undergoing elective PCI to reduce the incidence of myocardial periprocedural necrosis. The ROMA II trial. Int J Cardiol. 2013, 168:3715-3720. 10.1016/j.ijcard.2013.06.017

10. Kim JS, Kim J, Choi D, et al: Efficacy of high-dose atorvastatin loading before primary percutaneous coronary intervention in ST-segment elevation myocardial infarction: the STATIN STEMI trial. JACC Cardiovasc Interv. 2010, 3:332-339. 10.1016/j.jcin.2009.11.021

11. Liu HL, Yang Y, Yang SL, et al.: Administration of a loading dose of atorvastatin before percutaneous coronary intervention prevents inflammation and reduces myocardial injury in STEMI patients: a randomized clinical study. Clin Ther. 2013, 35:261-272. 10.1016/j.clinthera.2013.01.009

12. Briguori C, Visconti G, Focaccio A, et al: Novel approaches for preventing or limiting events (Naples) II trial: impact of a single high loading dose of atorvastatin on periprocedural myocardial infarction. J Am Coll Cardiol. 2009, 54:2157-2163. 10.1016/j.jacc.2009.07.005

13. Di Sciascio G, Patti G, Pasceri V, et al.: Efficacy of atorvastatin reload in patients on chronic statin therapy undergoing percutaneous coronary intervention: results of the ARMYDARECAPTURE (atorvastatin for reduction of myocardial damage during angioplasty) randomized trial. J Am Coll Cardiol. 2009, 54:558-565. 10.1016/j.jacc.2009.05.028

14. Patti G, Pasceri V, Colonna G, et al: Atorvastatin pretreatment improves outcomes in patients with acute coronary syndromes undergoing early percutaneous coronary intervention: results of the ARMYDA-ACS randomized trial. J Am Coll Cardiol. 2007, 49:1272-1278. 10.1016/j.jacc.2007.02.025

15. Gibson CM, Pride YB, Hochberg CP, et al.: Effect of intensive statin therapy on clinical outcomes among patients undergoing percutaneous coronary intervention for acute coronary syndrome. PCI-PROVE IT: A PROVE IT-TIMI 22 (pravastatin or atorvastatin evaluation and infection therapy-thrombolysis in myocardial infarction 22) substudy. J Am Coll Cardiol. 2009, 54:2290-2295. 10.1016/j.jacc.2009.09.010

16. Sardella G, Conti G, Donahue M, et al: Rosuvastatin pretreatment in patients undergoing elective PCI to reduce the incidence of myocardial periprocedural necrosis: the ROMA trial. Catheter Cardiovasc Interv. 2013, 81:36-43. 10.1002/ccd.24403

17. Gao Y, Jia ZM, Sun YJ, et al.: Effect of high-dose rosuvastatin loading before percutaneous coronary intervention in female patients with non-ST-segment elevation acute coronary syndrome. Chin Med J. 2012, 125:2250-2254.

18. Wang Z, Dai H, Xing M, et al: Effect of a single high loading dose of rosuvastatin on percutaneous coronary intervention for acute coronary syndromes. J Cardiovasc Pharmacol 
Ther. 2013, 18:327-333. 10.1177/1074248412474346

19. Atar S, Ye YM, Lin Y, et al: Atorvastatin-induced cardioprotection is mediated by increasing inducible nitric oxide synthase and consequent S-nitrosylation of cyclooxygenase-2. Am J Physiol Heart Circ Physiol. 2006, 290:1960-1968. 10.1152/ajpheart.01137.2005

20. Liuni A, Luca MC, Gori T, et al.: Rosuvastatin prevents conduit artery endothelial dysfunction induced by ischemia and reperfusion by a cyclooxygenase-2-dependent mechanism. J Am Coll Cardiol. 2010, 55:1002-1006. 10.1016/j.jacc.2009.11.046

21. Van Hecken A, Schwartz JI, Depre M, et al: Comparative inhibitory activity of rofecoxib, meloxicam, diclofenac, ibuprofen, and naproxen on COX-2 versus COX-1 in healthy volunteers. J Clin Pharmacol. 2000, 40:1109-1120.

22. Saini MK, Kaur J, Sharma P, et al.: Chemopreventive response of diclofenac, a non-steroidal anti-inflammatory drug in experimental carcinogenesis. Nutr Hosp. 2009, 24:717-723.

23. Vaish V, Tanwar L, Kaur J, et al.: Chemopreventive effects of non-steroidal anti-inflammatory drugs in early neoplasm of experimental colorectal cancer: an apoptosome study. J

Gastrointest Cancer. 2011, 42:195-203. 10.1007/s12029-010-9188-2

24. Muscara MN, McKnight W, Lovren F, et al.: Antihypertensive properties of a nitric-oxide releasing naproxen derivative in two-kidney, one-clip rats. Am J Physiol Heart Circ Physiol. 2000, 279:528-535.

25. Naidu PS, Booker L, Cravatt BF, et al.: Synergy between enzyme inhibitors of fatty acid amide hydrolase and cyclooxygenase in visceral nociception. J Pharmacol Exp Ther. 2009, 329:4856. 10.1124/jpet.108.143487

26. Ravingerova T, Matejikova J, Neckar J, et al.: Differential role of PI3K/Akt pathway in the infarct size limitation and antiarrhythmic protection in the rat heart. Mol Cell Biochem. 2007, 297:111-120. 10.1007/s11010-006-9335-Z

27. Walker MJ, Curtis MJ, Hearse DJ, et al: The Lambeth conventions: guidelines for the study of arrhythmias in ischemia infarction, and reperfusion. Cardiovasc Res. 1988, 22:447-455. 10.1093/cvr/22.7.447

28. Thuc LC, Teshima Y, Takahashi N, et al: Cardioprotective effects of pravastatin against lethal ventricular arrhythmias induced by reperfusion in the rat heart. Circ J. 2011, 75:1601-1608. 10.1253/circj.CJ-10-1139

29. Chen J, Nagasawa Y, Zhu BM, et al.: Pravastatin prevents arrhythmias induced by coronary artery ischemia/reperfusion in anesthetized normocholesterolemic rats. J Pharmacol Sci. 2003, 93:87-94. 10.1254/jphs.93.87

30. Bhatt DL, Scheiman J, Abraham NS, et al.: ACCF/ACG/AHA 2008 expert consensus document on reducing the gastrointestinal risks of antiplatelet therapy and NSAID use: a report of the American College of Cardiology Foundation Task Force on clinical expert consensus documents. Circulation. 2008, 118:1894-1909. 10.1161/CIRCULATIONAHA.108.191087 